\title{
Innovation Communities For Business Research
}

\author{
Bing $\mathrm{Wu}^{1}$, Chenyan Zhang ${ }^{2}$ \\ ${ }^{1}$ School of Economics and Management, Tongji University, Shanghai, China \\ ${ }^{2}$ Logistics Research Center, Shanghai Maritime University, Shanghai, China
}

Keywords: innovation communities, business value, social media

Abstract. This article focuses on a review of innovation communities for business from science citation index expanded (SCI-EXPANED) and Social Sciences Citation Index (SSCI) database on web of science, concerning the rapid growth of interest in understanding innovation communities. Research results indicate that (1) the average number of published items is 1 in each year from 2011 to present; accordingly citations mainly distributes in recent 4 years, reaching climax of 27 in 2015; (2) the main research area is ENGINEERING, accounting for $50.000 \%$, then followed by COMPUTER SCIENCE and INOFRMATION SCIENCE LIBRARY SCIENCE of $33.3337 \%$ respectively; (3) in the view of document types, $83.333 \%$ document is article; (4) Categories of COMPUTER SCIENCE INFORMATION SYSTEMS, ENGINEERING INDUSTRIAL, and INFORMATION SCIENCE LIBRARY SCIENCE rank in the top 3, accounting for 33.333\% respectively. Overall, the related research topics can be classified into five aspects: business value of online innovation communities, value co-creation and co-Innovation, selective openness on value Creation, social innovation process and idea launchers for creating value.

\section{Introduction}

With the advances in information technology (IT), social media technologies support a large volume of user-generated content that provides opportunities and challenges for business transformation [1]. In this sense, social media technologies represent a promising paradigm with customer communities to emphasis on core competencies, personalization and innovation, supported by collaborative mechanisms. As firms increasingly leverage IT in various innovation activities [2], they can use a particular online innovation communities for open innovation by crowdsourcing the ideas about new products, services and processes.

Thus, it is often suggests that online innovation communities are valuable for crowdsourcing by enabling firms to collect large amount of user-generated ideas [3]. Although the application of online innovation communities is popular with the assumption that it can create business value, the extent to which online innovation communities actually contribute business value to firms remains largely unclear. In particular, how firms can derive business value from their strategic use of online innovation communities has not been fully understood [4].

The rest of this article is organized as follows: Section 2 surveys the relating results analysis of innovation community for business literatures. Section 3 briefly summarizes related work within this topic. Section 4 concludes the article with a summary of our key results and discusses new opportunities for future research..

\section{Analysis Results of Relating Literatures}

According to Science Citation Index Expanded and Social Sciences Citation Index Database in web of science, 6 articles title as "innovation community business" excluding the conferences papers are found in related discipline in recent 9 years.

Results of Citation Report. Published items in each year were shown in Fig 1, which illustrated the tendency of relating research from 2011 to present with the average number of 1. Accordingly, citations increased from 2013 and the highest citations of 27 happened in 2015, as shown in Fig 2. 


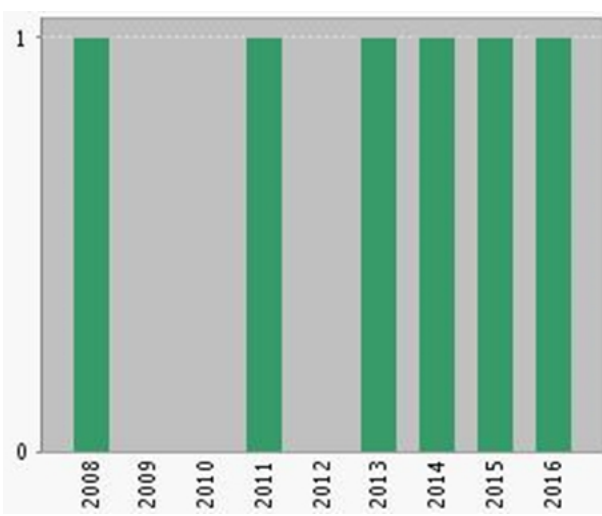

Fig 1.Published Items in Each Year

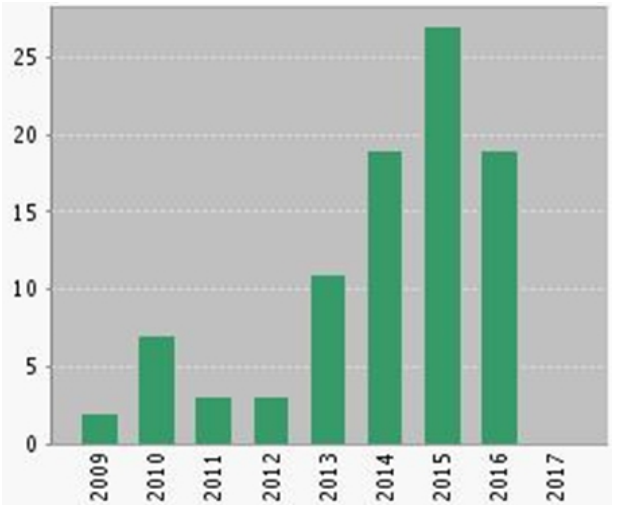

Fig 2. Citations in Each Year

Results of Research Areas. According to Table 1, 50.000\% of the research areas is in ENGINEERING, then $33.333 \%$ in COMPUTER SCIENCE and INFORMATION SCIENCE LIBRARY SCIENCE, respectively.

Table 1. Research Areas

\begin{tabular}{ccc}
\hline Research Areas & Record Count & $\%$ of 6 \\
\hline ENGINEERING & 3 & $50.000 \%$ \\
COMPUTER SCIENCE & 2 & $33.333 \%$ \\
INFORMATION SCIENCE LIBRARY SCIENCE & 2 & $33.333 \%$ \\
\hline
\end{tabular}

Results of Document Types. Concerning document types, article accounts for $83.333 \%$, as shown in Table 2.

Table 2. Document Types

\begin{tabular}{ccc}
\hline Document Types & Record Count & $\%$ of 6 \\
\hline ARTICLE & 5 & $83.333 \%$ \\
\hline
\end{tabular}

Results of Web of Science Categories. Based on web of science categories, COMPUTER SCIENCE INFORMATION SYSTEMS, ENGINEERING INDUSTRIAL, and INFORMATION SCIENCE LIBRARY SCIENCE ranks in the top 3, accounting for 33.333\% respectively, as shown in Table 3.

Table 3. Web of Science Categories

\begin{tabular}{ccc}
\hline Web of Science Categories & Record Count & $\%$ of 6 \\
\hline COMPUTER SCIENCE INFORMATION SYSTEMS & 2 & $33.333 \%$ \\
ENGINEERING INDUSTRIAL & 2 & $33.333 \%$ \\
INFORMATION SCIENCE LIBRARY SCIENCE & 2 & $33.333 \%$ \\
\hline
\end{tabular}

\section{Relating Topics of Innovation Communities}

We review areas of research covered by papers in innovation communities to take the current state and to propose directions for future research. Generally, relating topics and be identified from five aspects: business value of online innovation communities, value co-creation and co-Innovation, selective openness on value Creation, social innovation process and idea launchers for creating value.

Business Value of online innovation communities. Social media technologies allow user-generated content and provide new opportunities and challenges for firms to transform their business. In particular, more and more firms have started strategically using the online user innovation communities for open innovation initiatives [5].

The extent to which firms are able to derive business value from online user innovation communities, however, has not been systematically examined. Drawing on a multi-theoretical foundation from the framework of dynamic capabilities and the view of innovation value chain, reference [6] conceptualize two enabled capabilities, which are ideation capability and implementation capability. Ideation capability is related to collecting user-generated ideas about potential innovation from online user innovation communities.

Value Co-Creation and Co-Innovation. Online innovation communities are active entities continuously adapting to their environment in order to enhance their capabilities to respond to 
short-term business opportunities, and therefore allow their business ecosystems to follow the rhythm of industry dynamics [7]. Value co-creation is the new trend in open business models trying to integrate organizations' competencies into network and community formations for the co-creation of the next level of value for products, services and experiences to be launched into the market.

Reference [8] presents a literature review on value co-creation and co-innovation concepts and styles, and proposes a reference framework for creating interface networks as enablers for linking networked organizations and customer communities in order to support the establishment of sustainable user-driven and collaborative innovation networks.

Selective Openness on Value Creation. With the rise of open innovation research and practice, open innovation research and practice recognize the important role of external sources in value creation [9]. Meanwhile, firms need to retain exclusive control over some essential components to capture value from their product and/or service system.

Reference [10] proposes on selective openness as a key variable and investigates how it affects value creation by external sources, specifically the members of user innovation communities by analyzing some of the trade-offs between openness to external value creation and closeness for internal value capture.

Social Innovation process. Fujitsu Laboratories has put social innovation process into practice at various places in Japan with a focus on key social themes. These activities have revealed that many existing measures are problematic in terms of economic sustainability. Reference [11] describes the social innovation process as Figure 3, presents four case studies, and introduces the concepts of a community-based value chain for achieving the new relationships needed for solving social problem and of a participatory smart community for achieving new forms of mutual assistance among residents through information and communications technology (ICT).

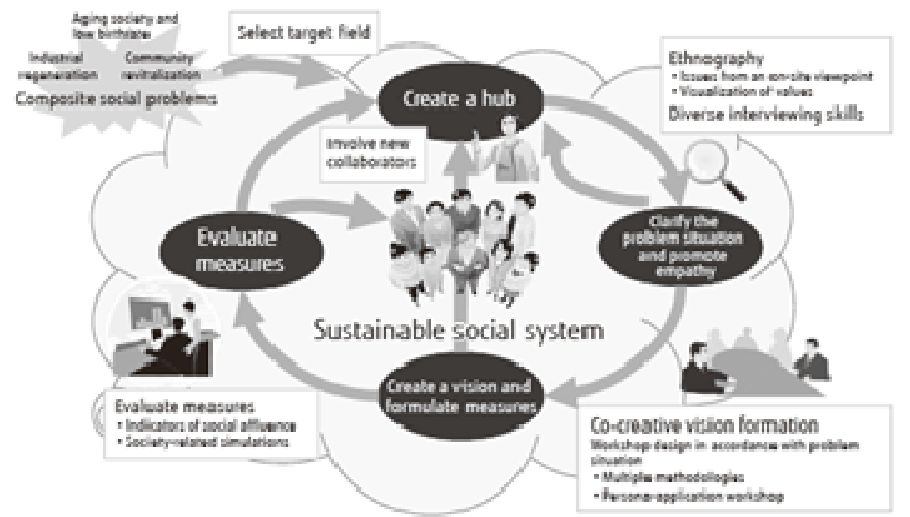

Figure 3 Social Innovation Process

Idea launchers for creating value. Successful open innovation requires that many ideas be posted by a number of users and that the posted ideas be evaluated to find ideas of high quality[12]. To answer two questions: what are the factors which differentiate the idea launchers from non-launchers and how to identify and predict potential idea launchers in advance, basic features were extracted from idea, comment and added further features obtained from sentiment analysis on ideas and comments to develop classification models to identify potential idea launchers, using data mining techniques.

Considering the fact that idea launchers have contributed to enhancing the quantity and quality of innovation significantly more than non-launchers in our target community, the prediction of idea launchers is distinctly useful for the better management of user innovation communities. In that sense, reference [13] tries to mitigate the information overload problem by identifying potential idea launchers by choosing MyStarbucksIdea.com as a target innovation community.

\section{Conclusions}

Although the observable events that resulted from ideation capability and implementation capability of online innovation communities in the empirical test had measured, these measures may not fully 
capture all aspects of capabilities in online innovation communities. Future research can adopt survey methods and develop more fine-grained measures. Moreover, the longitudinal data are limited to representative early adopters of online innovation communities, future studies should collect data from other firms and elaborate findings from various industries, in order to improve the reliability of the results to find a way of managing customers' ideas more effectively and efficiently.

To acquire an effective involvement of customers in communities and organizations in collaborative networks to create the synergy necessary, the future research should investigate and predict which components and forms of openness matter to users, therefore extend the understanding of the optimal degree, nature, and scope of openness.

\section{References}

[1] Jarvenpaa, S.L., Tuunainen, V.K. (2013). How Finnair socialized customers for service co-creation with social media. MIS Quarterly Executive 12 (3), 125-136.

[2] Dong, J.Q., Yang, C.-H. (2015). Information technology and organizational learning in knowledge alliances and networks: evidence from U.S. pharmaceutical industry. Information and Management 52 (1), 111-122.

[3] Huang, Y., Singh, P.V., Srinivasan, K. (2014). Crowdsourcing new product ideas under consumer learning. Management Science 60 (9), 2138-2159

[4] Bayus, B.L. (2013). Crowdsourcing new product ideas over time: An analysis of the Dell IdeaStorm community. Management Science 59 (1), 226-244.

[5] Nambisan, S. (2013). Information technology and product/service innovation: a brief assessment and some suggestions for future research. Journal of Association for Information Systems 14 (4), $215-226$.

[6] Dong, J. Q., Wu, W. F. (2015). Business value of social media technologies: Evidence from online user innovation communities. Journal of Strategic Information Systems, 24(2), 113-127

[7] Fuchs, C., Schreier, M. (2011). Customer empowerment in new product development. Journal of Product Innovation Management 28 (1), 17-32.

[8] Romero, D., Molina, A. (2011).Collaborative networked organisations and customer communities: value co-creation and co-innovation in the networking era. Production Planning \& Control, 22(5-6), 447-472

[9] Alexy, O., G. George, and A. Salter (2013). Cui bono? The selective revealing of knowledge and its implications for innovative activity. Academy of Management Review 38 (2): 270-91.

[10] Balka, K., Raasch, C., Herstatt, C. (2014). The Effect of Selective Openness on Value Creation in User Innovation Communities. Journal of Product Innovation Management, 31(2), 392-407

[11]Ishigaki, K., Sashida, N (2013). Use of Social Innovation to Solve Problems at the Community Level and Create New Businesses in the Social Domain. Fujitsu Scientific \& Technical Journal, 49(4): 430-439

[12]Lee, H., Han, J., Suh, Y. (2014), "Gift or threat? An examination of voice of the customer: the case of MyStarbucksIdea.com”, Electronic Commerce Research and Applications, 13(3), 205-219.

[13]Lee, H., Suh, Y. (2016) Who creates value in a user innovation community? A case study of MyStarbucksIdea.com. Online Information Review, 40(2), 170-186 